\title{
Air-heated solid-gas reaction setup for in situ neutron powder diffraction
}

\author{
Ahlburg, Jakob Voldum; Canévet, Emmanuel; Christensen, Mogens
}

Published in:

Journal of Applied Crystallography

Link to article, DOI:

$10.1107 / \mathrm{S} 1600576719008161$

Publication date:

2019

Document Version

Publisher's PDF, also known as Version of record

Link back to DTU Orbit

Citation (APA):

Ahlburg, J. V., Canévet, E., \& Christensen, M. (2019). Air-heated solid-gas reaction setup for in situ neutron powder diffraction. Journal of Applied Crystallography, 52(4), 761-768.

https://doi.org/10.1107/S1600576719008161

\section{General rights}

Copyright and moral rights for the publications made accessible in the public portal are retained by the authors and/or other copyright owners and it is a condition of accessing publications that users recognise and abide by the legal requirements associated with these rights.

- Users may download and print one copy of any publication from the public portal for the purpose of private study or research.

- You may not further distribute the material or use it for any profit-making activity or commercial gain

- You may freely distribute the URL identifying the publication in the public portal

If you believe that this document breaches copyright please contact us providing details, and we will remove access to the work immediately and investigate your claim. 


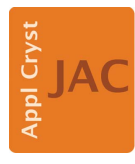

JOURNAL OF

APPLIED

CRYSTALLOGRAPHY

ISSN 1600-5767

Received 28 January 2019

Accepted 6 June 2019

Edited by G. J. McIntyre, Australian Nuclear Science and Technology Organisation, Lucas Heights, Australia

Keywords: in situ; neutron powder diffraction; solid-gas reactions; single-crystal sapphire; exchange-spring magnets.

Supporting information: this article has supporting information at journals.iucr.org/j

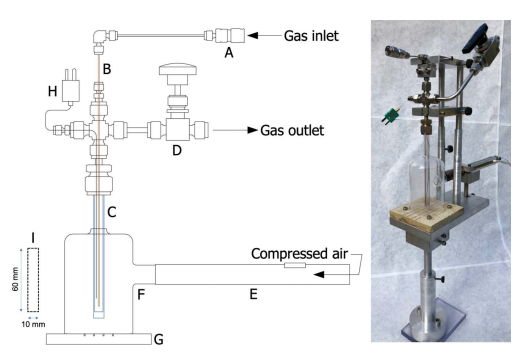

(C) 2019 International Union of Crystallography

\section{Air-heated solid-gas reaction setup for in situ neutron powder diffraction}

\author{
Jakob Voldum Ahlburg, ${ }^{a}$ Emmanuel Canévet ${ }^{\mathrm{b}, \mathrm{c}}$ and Mogens Christensen ${ }^{\mathrm{a} *}$
}

${ }^{a}$ Center for Materials Crystallography, Department of Chemistry and iNANO, Aarhus University, Langelandsgade 140, 8000 Aarhus, Denmark, 'baboratory for Neutron Scattering and Imaging, Paul Scherrer Institut (PSI), 5232 Villigen, Switzerland, and ' Department of Physics, Technical University of Denmark, 2800 Kongens Lyngby, Denmark.

*Correspondence e-mail: mch@chem.au.dk

The design and function of a reduction furnace, specially designed for solid-gas in situ monochromatic angular dispersive neutron powder diffraction, is presented. The functionality is demonstrated by performing a reduction experiment of $\mathrm{CoFe}_{2} \mathrm{O}_{4}$ nanoparticles at the instrument DMC at SINQ. Heating is provided by an air gun, allowing the sample to reach temperatures in the range of $300-973 \mathrm{~K}$ within less than $5 \mathrm{~min}$. The setup is based on a single-crystal sapphire tube with one end closed. A $\varphi$ scan of the tube reveals its single-crystal nature, through strong single-crystal reflections, while the remaining background is very low, uniform and flat. $\mathrm{CoFe}_{2} \mathrm{O}_{4}$ was reduced using a time resolution of $8 \mathrm{~min}$ and a sample volume of $\sim 2 \mathrm{~cm}^{3}$. By means of sequential Rietveld refinement of the in situ neutron diffraction data, a two-step reduction mechanism was discovered: $\mathrm{CoFe}_{2} \mathrm{O}_{4} \rightarrow \mathrm{Co}_{0.33} \mathrm{Fe}_{0.67} \mathrm{O} \rightarrow \mathrm{CoFe}_{2}$. The setup offers high temperatures, fast temperature stability, large sample volumes and respectable time resolution. The setup has proven to be ideal to carry out investigations of advanced materials under realistic conditions. The ability to investigate real materials in real time under realistic conditions may be a significant advantage for scientific investigations as well as for industrial applications.

\section{Introduction}

In modern-day society, the value of solid-gas reactions cannot be underestimated. Simple reactions from our everyday life involve oxidation of steel or copper, as can be seen in cars and copper roofing, respectively. Steel hardening can involve nitridation of low-carbon steel to enhance its mechanical properties (Meka et al., 2016; Akhtar et al., 2012). For energy storage, hydrogen is expected to play a crucial role, and the materials involved are carefully designed nano-sized crystallites, which can absorb and desorb hydrogen through a controlled process (Sakintuna et al., 2007; Züttel, 2004). Advanced magnetic materials such as $\alpha^{\prime \prime}-\mathrm{Fe}_{16} \mathrm{~N}_{2}$ and $\gamma-\mathrm{Fe}_{4} \mathrm{~N}$ can be made via a two-step mechanism, where $\mathrm{FeO}$ is first reduced under heat and hydrogen $\left(\mathrm{H}_{2}\right)$ gas and the product is subsequently treated with gaseous ammonia $\left(\mathrm{NH}_{3}\right)$ (Bhattacharyya, 2015). These processes typically take place at elevated temperature and pressure. In order to optimize these materials, it is of utmost importance to understand the reaction mechanisms in question. In situ powder diffraction can be used to give information about the crystalline phases forming during a chemical reaction between a solid and a gas.

A typical experiment for investigating changes in crystal structures would be in situ X-ray diffraction performed at a synchrotron, which allows a very high time resolution $(\sim \mathrm{ms})$ 
and very small beam size $(\sim \mu \mathrm{m})$ to look at changes locally in a small sample $(\sim \mathrm{mg})$. However, in many of the abovementioned experiments, a large sample may be advantageous, and X-rays are challenged when it comes to light elements $(Z<10)$, as these scatter X-rays weakly compared with heavier elements $(Z>20)$ (Giacovazzi et al., 2011). A solution to this problem is to use neutrons instead of X-rays. Neutrons interact more weakly with matter than X-rays, and consequently neutrons can penetrate through a large sample volume and bulky sample environment. Neutrons also have the ability to distinguish neighbouring elements, as the scattering length $b$ changes erratically with atomic number $Z, e . g$. $\mathrm{Fe}(Z=26), b_{\mathrm{Fe}}=9.45 \mathrm{fm}$ and $\operatorname{Co}(Z=27), b_{\mathrm{Co}}=2.49 \mathrm{fm}$ (Rauch \& Waschkowski, 2003), in contrast to the linear relationship between scattering power and $Z$ for X-rays. Neutrons allow detection of light atoms such as hydrogen, oxygen and nitrogen in the presence of heavy elements, as well as distinguishing between neighbouring atoms. Finally, the neutron carries a spin, which can interact with the atomic magnetic dipolar moment allowing determination of the magnetic structure at the atomic level (Zaliznyak \& Lee, 2004).

Neutrons allow for bulky sample environments, which in turn allows experimentalists to approach industrial setups. However, it is typically desirable to have unhindered access to the scattering plane. Therefore, special sample environments have to be developed for neutron scattering experiments. For solid-gas reactions the goal is to have a sample environment that can deliver highly reactive and/or flammable gases and a large amount of heat to the system in a controlled manner, while also granting access for the neutrons (Götze et al., 2018). A suitable in situ neutron diffraction solid-gas reaction setup has to fulfil the following criteria:

(a) Controllable gas flow and pressure

(b) Corrosion resistance

(c) Ability to heat to high temperatures with a fast heating rate

(d) Pressure resistance

(e) High temperature stability

(f) No hydrogen embrittlement

(g) Inert surfaces

(h) Clear optical path for the neutron

(i) Transparency to neutrons (no parasitic reflections, low background, low incoherent scattering)

(j) Transparency to light (allowing other spectroscopic techniques)

With these criteria in mind, the most crucial part of designing the sample environment is finding a material that can fulfil most of these criteria. A hard metallic alloy may seem a good option, because of its excellent mechanical and thermal stability (Chen et al., 2012; Peters et al., 2012; Klotz, 2012). However, owing to the polycrystalline nature of steel, Inconel, aluminium etc., they will typically contribute significantly to the diffraction pattern with strong parasitic reflections. To avoid these reflections, null-scattering materials such as $\mathrm{Ti}_{1-x} \mathrm{Zr}_{x}$ have been developed using different $x$ stoichiometries (Sidhu et al., 1956; Okuchi et al., 2015). Unfortunately, these show hydrogen embrittlement and are therefore excluded for experiments using hydrogen. Amorphous materials like quartz have also been widely used but have a distinct structured diffraction background (Hansen et al., 2015). Single-crystal sapphire (SCS) solves the problem by offering a low background, and the inevitable single-crystal diffraction peaks can be avoided in monochromatic angular dispersive neutron powder diffraction by ensuring that the reciprocal lattice vector $\mathbf{H}$ of the single crystal and the scattering vector $\mathbf{Q}$ do not coincide. Fulfilling the Laue condition $\mathbf{H}=\mathbf{Q}$ (AlsNielsen \& McMorrow, 2011) can be avoided by controlling the orientation of the SCS sample holder. SCS can be manufactured to withstand high pressures $\left(>100\right.$ bar; 1 bar $\left.=10^{5} \mathrm{~Pa}\right)$ and has an operating temperature of up to $2270 \mathrm{~K}$ (https:// www.crytur.cz). Furthermore, it has the advantage of being transparent and thereby allows simultaneous employment of complementary light-based techniques (Kohlbrecher et al., 2007). The disadvantages to using SCS are the risk of sudden rupture during high-pressure experiments and the release of flammable or toxic gases, which can be prevented by appropriate shielding of the surrounding equipment and suction on the experiment.

Sample environments for in situ neutron diffraction solidgas reactions using SCS already exist (Kohlmann et al., 2009; Widenmeyer et al., 2013; Rondinone et al., 2003; Götze et al., 2018). Kohlmann et al. (2009) reported SCS setups that allow pressures of up to $80-160$ bar and a temperature range of room temperature (RT) to $700 \mathrm{~K}$. By measuring an $\omega$ scan of the SCS tube at $\chi=0^{\circ}$ in the four-circle diffractometer geometry described by Busing \& Levy (1967), Kohlmann and co-workers succeeded in finding a suitable $\omega$ position where the background was only affected around $2 \theta \simeq 90^{\circ}$. In other words, the SCS can be oriented so that parasitic scattering can be avoided. The SCS sample holder described in the literature was manufactured by drilling a hole into an SCS rod, with an inner diameter of $6 \mathrm{~mm}$ and an outer diameter of $12 \mathrm{~mm}$ (Götze et al., 2018). The sample is heated using laser heating with a power input of $80 \mathrm{~W}$. This setup is optimized for highpressure studies at intermediate temperatures.

In the present study, we report on an in situ neutron powder diffraction solid-gas reaction setup optimized for experiments with gas flow and a very rapid heating. Temperatures of $973 \mathrm{~K}$ can be reached using a hot-air gun with a power input of 1000 W. Furthermore, a test experiment was carried out at the neutron instrument DMC at SINQ (https://www.psi.ch/sinq/ $\mathrm{dmc} /$ ), in which the magnetic compound $\mathrm{CoFe}_{2} \mathrm{O}_{4}$ was partially reduced to $\mathrm{CoFe}_{2}$ using a flow of $5 \% \mathrm{H}_{2} /$ Ar to realize an exchange-spring magnet.

\section{Materials and methods}

\subsection{Synthesis of $\mathrm{CoFe}_{2} \mathrm{O}_{4}$ nanopowders}

The synthesis of $\mathrm{CoFe}_{2} \mathrm{O}_{4}$ followed the steps reported in the literature (Andersen et al., 2019; Eikeland et al., 2017; Stingaciu et al., 2017; Andersen \& Christensen, 2015). In short, a stoichiometric 1:2 molar ratio of $\mathrm{Co}: \mathrm{Fe}$ was mixed directly in a Teflon-lined steel autoclave using aqueous solutions of $3.0 \mathrm{M}$ 
$\mathrm{Co}\left(\mathrm{NO}_{3}\right)_{2} \cdot 6 \mathrm{H}_{2} \mathrm{O}$ and $2.3 M \mathrm{Fe}\left(\mathrm{NO}_{3}\right)_{3} \cdot 9 \mathrm{H}_{2} \mathrm{O}$ (reagent grade, Sigma-Aldrich). A $16 \mathrm{M} \mathrm{NaOH}$ solution was added dropwise in slight excess $\left(\mathrm{OH}^{-}: \mathrm{NO}_{3}{ }^{-}\right.$molar ratio of 1:1.25) under constant stirring. The sealed autoclave was placed in a $513 \mathrm{~K}$ preheated oven for $2 \mathrm{~h}$. The obtained dispersion of nanoparticles was washed and centrifuged five times in demineralized water and dried in a vacuum oven at $323 \mathrm{~K}$ for approximately $24 \mathrm{~h}$.

\subsection{Powder X-ray diffraction}

Diffraction data were collected on an in-house Rigaku SmartLab diffractometer using a Co target $(35 \mathrm{kV}, 170 \mathrm{~mA})$ in Bragg-Brentano mode. Rietveld analysis (Rietveld, 1969; Loopstra \& Rietveld, 1969) of the diffraction data was done using the FullProf suite (Rodríguez-Carvajal, 1993) to investigate the purity and apparent crystallite size of the sample prior to reduction. A NIST $\mathrm{LaB}_{6} 660 \mathrm{~B}$ standard was used to determine the peak broadening originating from the instrument.

\subsection{In situ setup}

A schematic and a photograph of the single-crystal sapphire air-gun heater setup (SAHS) are presented in Fig. 1. The sample is placed in an SCS tube with one end closed, with an outer diameter of $10 \mathrm{~mm}$, a height of $150 \mathrm{~mm}$ and a wall thickness of $1 \mathrm{~mm}$. The SCS was grown in one piece along the $c$ axis by the company Crytur with no additional mechanical machining (https://www.crytur.cz). The tube can withstand high pressures despite the relatively thin wall thickness of $1 \mathrm{~mm}$. The SCS tube was tested to 100 bar using water as pressure medium and a high-performance liquid chromatography pump (Prep Pump, LabAlliance). In the setup, the SCS

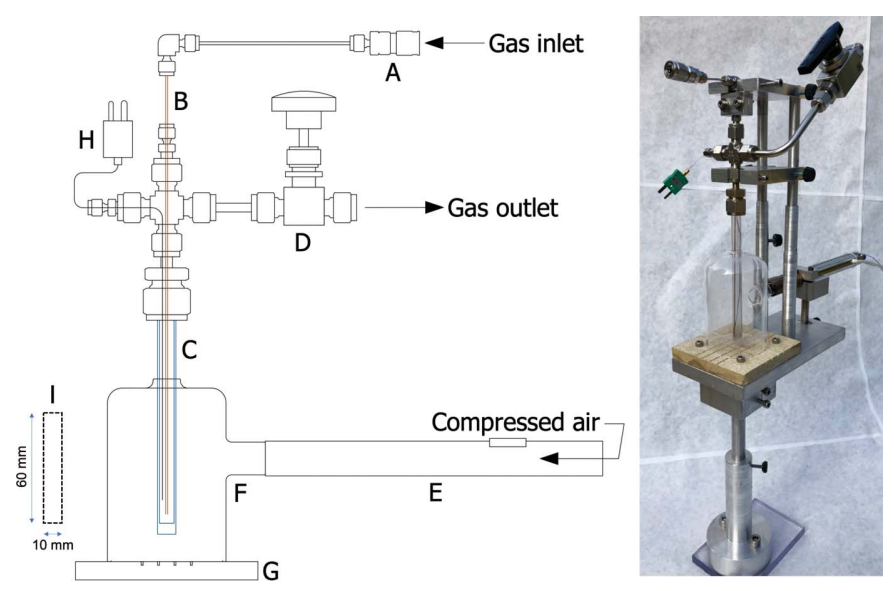

Figure 1

Sample environment. (Left) Schematic drawing of the setup. Gas flows through the system in the following order: A quick-fit connector, B fused silica tube, $\mathbf{C}$ SCS sample container, $\mathbf{D}$ outlet valve. The heater airflow goes through $\mathbf{E}$ Hi-Heater air gun, $\mathbf{F}$ heat confinement quartz dome, $\mathbf{G}$ ceramic insulator with air outlet grooves. H Thermocouple. I Typical neutron beam size of $10 \mathrm{~mm}$ by $60 \mathrm{~mm}$. (Right) Photograph of the setup with the vertical rotational axis through the centre of the sample container. tube is connected to standard Swagelok stainless steel fittings and sealed with a Teflon ferrule. A $\sim 0.5 \mathrm{~mm}$-diameter thermocouple is introduced into the setup through a $1 / 16^{\prime \prime}$ fitting using a Vespel ferrule. The thermocouple measures the temperature $10 \mathrm{~mm}$ above the bottom of the SCS tube. Gas flow is applied from the bottom of the tube through a fused silica tube with outer/inner diameter of $0.85 / 0.75 \mathrm{~mm}$, fastened with a $1 / 16^{\prime \prime}$ fitting using graphite ferrules. The gas bottle is connected through a quick-fit connection. The gas is released at the bottom of the SCS tube, flows up through the sample and escapes through the gas outlet valve at the top. The entire system from the gas bottle to the valve is a closed system, and inert samples can be loaded in a glovebox. It is likewise possible to prepare and extract air-sensitive samples from the system. The fused silica tube is fragile, and it is carefully held in place by specially designed holders fitting the Swagelok equipment. These holders also ensure the centring of the sample and allow adjustment of the sample height.

The SCS sample tube is lowered into a custom-made quartz dome which acts as heat shield and only allows hot air to escape through small pathways at the top and bottom of the dome. This traps the hot air around the sample and ensures a homogenous heating. The quartz dome only traps the hot air around the part of the sapphire tube containing the sample, while allowing the top of the tube to be air-cooled. This ensures that the Teflon ferrule does not melt when operating the setup at high temperatures $(>800 \mathrm{~K})$. The quartz dome has an inner diameter of $60 \mathrm{~mm}$, allowing typical radial collimators to suppress effectively any quartz scattering coming from the dome using an incident beam size of $10 \times 60 \mathrm{~mm}$. The heater and sample mounting shadows roughly $60^{\circ}$ in the detector plane, leaving a free optical path of roughly $300^{\circ}$.

\subsection{Pressurization and flow}

The pressure of the gas inlet is controlled by using a standard reduction valve. The flow of the gas is regulated by a flow meter with a flow range of $0-100 \mathrm{ml} \mathrm{min}^{-1}$. On the exhaust side of the setup, the pressure can be controlled in multiple ways. The system can be left open for ambient-pressure conditions inside the sapphire tube, a pressure relief valve can be attached to perform flow experiments at higher pressure, or a pump can be attached for vacuum or flow experiments at low pressures. Finally, the exhaust can be blocked by closing a simple ball valve to allow for non-flow high-pressure experiments. The valve also allows one to close the system completely after an experiment and easily transfer the whole setup to a glovebox to retrieve air-sensitive samples.

\subsection{Heating}

The air-gun heater is a Hi-Heater SAH-1-AFT-1000W from Hybec, Miyawaka Corporation, Japan (https://www.hybecusa. com/industrial-heaters/air-heater). It heats compressed dry air using an electrically heated coil to give a temperature range at the nozzle of RT-1273 K. Any temperature within this range can be reached and stabilized within 15-20 s. Furthermore, the heater offers active cooling of the sample as the heater itself 
will cool to room temperature within approximately $30 \mathrm{~s}$ when the power is turned off. This allows for rapid heating and cooling of the sample. The air heater comes with a controller module with a built-in proportional-integral-derivative (PID) controller and fail-safe operation in case of overheating or missing airflow. The controller allows setting the air-inlet pressure, the air-outlet flow and the nozzle temperature.

\subsection{General experimental procedure}

The setup can be installed on the sample table of almost any monochromatic neutron diffractometer as the footprint is relatively small and good angular access is provided, except at the position of the hot-air gun. The SCS tube is loaded with $\sim 2 \mathrm{~cm}^{3}$ of sample, giving a sample height of $\sim 40 \mathrm{~mm}$ depending on sample density. The fused silica gas inlet is inserted into the sample tube with a flow rate of $10 \mathrm{ml} \mathrm{min}^{-1}$ to avoid any clogging of the inlet. The sample tube is then fastened to the Swagelok fittings, and once a steady gas flow is ensured throughout the sample, the flow rate is adjusted to the intended experimental value. The gas flow makes the sample act as a fluidized bed, and the height typically increases by $\sim 50 \%$ with little fluctuation during an experiment. The total height of the sample must never exceed $60 \mathrm{~mm}$ in order to probe the whole sample volume at all times when using a fixed neutron beam size of $10 \times 60 \mathrm{~mm}$. The sample tube is inserted into the glass dome and centred with respect to the neutron beam.

\subsection{Data collection}

A powder diffraction pattern with good statistics is acquired from the pristine sample at RT, before starting any heat treatment. This ensures that the sample is in the beam and avoidance of sapphire Bragg reflections hitting the detector, and it produces high-statistics data for the initial refinements. The neutron count is changed to fit a desired time resolution and the heater is turned on. At the end of the experiment the heater is turned off and the sample is allowed to cool to RT, at which point another data set with high statistics is acquired. Experiments typically run for 3-15 h with a time resolution of $8 \mathrm{~min}$ per pattern.

\subsection{Reduction of $\mathrm{CoFe}_{2} \mathrm{O}_{4}$}

The reduction of $\mathrm{CoFe}_{2} \mathrm{O}_{4}$ spinel was selected as a case study on the instrument DMC at SINQ. A wavelength of $2.46 \AA$ was selected and a $2 \theta$ range of $12.8-92.9^{\circ}$ was covered with an angular resolution of $0.1^{\circ}$. Each pattern was collected for a total neutron monitor count of 50400 , which is equivalent to $8 \mathrm{~min}$ per pattern in steady-state operation of the neutron source. In the

Figure 2 given example, a total of 39 patterns were collected. The pristine sample, consisting of $13 \mathrm{~nm}$-sized $\mathrm{CoFe}_{2} \mathrm{O}_{4}$ nanocrystallites, was heated to a sample temperature of $758 \mathrm{~K}$ while flowing $100 \mathrm{ml} \mathrm{min}^{-1}$ of $5 \% \mathrm{H}_{2}$ in Ar through the sample.

\section{Results}

\subsection{Temperature calibration}

A temperature calibration of the setup was performed using the thermocouple inside the sapphire tube to measure the sample temperature while monitoring the exhaust temperature of the heat gun. Quartz sand was used as sample for the temperature calibration. The heat gun used a compressed-air flow rate of $481 \mathrm{~min}^{-1}$ at a pressure of $0.6 \mathrm{MPa}$ and set temperatures in the range of RT- $1273 \mathrm{~K}$ in steps of $100 \mathrm{~K}$. For each temperature step the heater nozzle reached the set temperature within $20 \mathrm{~s}$. The setup was allowed to thermally stabilize for $10 \mathrm{~min}$ before the sample temperature was read out. The obtained calibration data are plotted in Fig. 2(a). The data follow a linear trend and the maximum sample temperature reached was $973 \mathrm{~K}$. The sample temperature was followed as a function of time to determine the time needed to obtain a stable sample temperature. The set temperature of the heater in this case was $1273 \mathrm{~K}$. The data are presented in Fig. 2(a) using a red line. The sample temperature increases rapidly as the heater is turned on and stabilizes within $2 \mathrm{~K}$ of the final temperature in less than $5 \mathrm{~min}$.

The calibration curve is used as a tool to estimate the heater set temperature for specific experimental sample temperatures. However, during an experiment the temperature is monitored in situ and might deviate slightly from the calibration as a result of the gas flow and thermal properties of the sample.

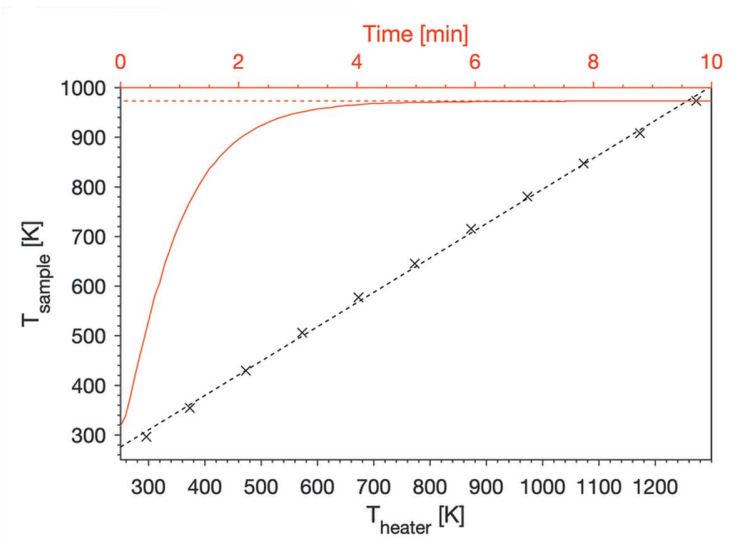

(a)

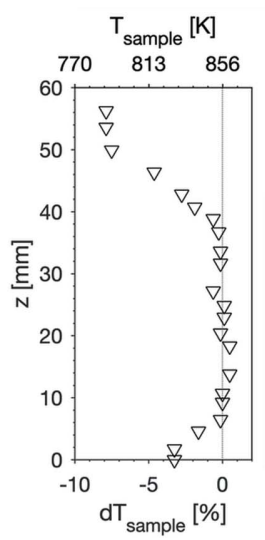

(b)

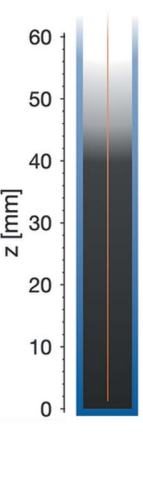

(c) (a) Temperature calibration of the sample versus heater temperature using quartz powder. The crosses are data points and the dashed black line represents the linear fit $T_{\text {sample }}=0.693$ (2) $T_{\text {heater }}+$ 102 (2) K. Error bars are within the size of the symbols. The full red line represents the heating of the sample at a constant heater temperature of $T_{\text {heater }}=1273 \mathrm{~K}$ as a function of time in steps of $5 \mathrm{~s}$. The sample temperature is stable after less than $5 \mathrm{~min}$. The red dashed line is a guide to the eye of the final temperature. (b) The change in sample temperature $\mathrm{d} T_{\text {sample }}$ as a function of height $z$ in the sample tube using a $\mathrm{CoFe}_{2} \mathrm{O}_{4}$ sample and a constant heater temperature of $T_{\text {heater }}=1073 \mathrm{~K}$. The reference sample temperature was set to $856 \mathrm{~K}$. (c) Schematic representation of the SCS sample holder containing $\mathrm{CoFe}_{2} \mathrm{O}_{4}$ as a function of height $z$ in the tube. 
(a)

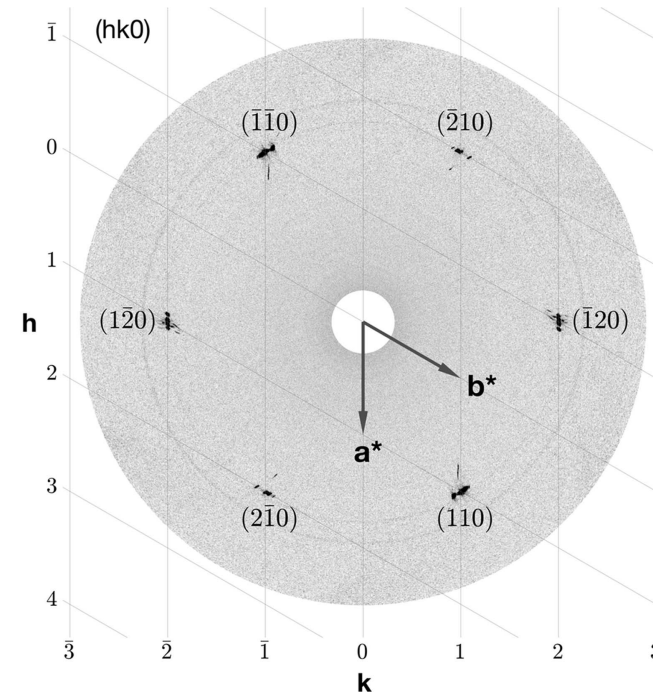

(b)

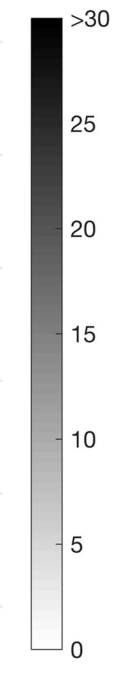

(c)
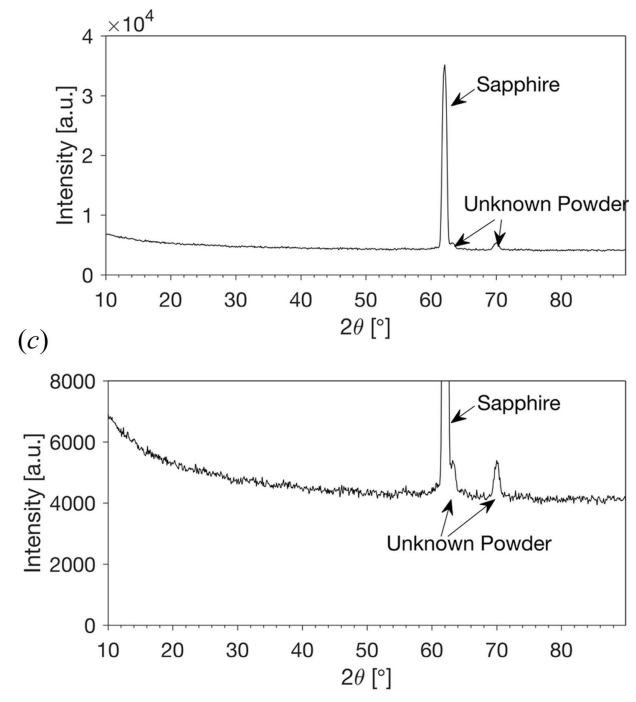

Figure 3

(a) $\varphi$ scan of the $h k 0$ reflections of the single-crystal sapphire sample holder. The reflections from the single-crystal sapphire are highlighted. (b) The azimuthally integrated $\varphi$ scan. The single-crystal sapphire peak is highlighted as well as powder peaks of an unknown origin. $(c)$ A zoom of $(b)$.

In order to evaluate the thermal stability throughout the sample, $2 \mathrm{~g}$ of $\mathrm{CoFe}_{2} \mathrm{O}_{4}$ was brought to thermal equilibrium using a heater temperature of $1073 \mathrm{~K}$, an $\mathrm{N}_{2}$ gas flow of $20 \mathrm{ml} \mathrm{min}{ }^{-1}$ and a back pressure of 2 bar. By changing the position of the thermocouple inside the SCS sample tube the change in sample temperature $\mathrm{d} T$ was measured as a function of height $z$ within the sample, as can be seen in Fig. 2(b). The changes in temperature were based on a sample temperature of $856 \mathrm{~K}$. The total height of the sample was initially $30 \mathrm{~mm}$ and rose to $50 \mathrm{~mm}$ once the flow of gas was applied, as seen in Fig. 2(c). The upper $10 \mathrm{~mm}$ had a low density of powder, which owing to the gas stirring quickly returned to the denser lower part of the sample.

The sample temperature is stable throughout most of the sample, except for the bottom part where the temperature deviates by up to $\sim 3.5 \%$ and the upper part where the temperature drops off as the thermocouple is no longer within the sample and ends with a deviation of $\sim 8 \%$ at $z=56 \mathrm{~mm}$.
However, owing to the stirring of the powder, most of the sample is always positioned in the thermally stable region of the SCS sample tube, and a single grain of powder would experience an almost identical thermal history throughout an experiment.

\section{2. $\varphi$ scan of the SCS sample holder}

To determine the background from the sample holder, a $\varphi$ scan of the empty SCS sample holder was made. Since $\chi=0^{\circ}$, $\omega$ coincides with $\varphi$. The $c$ axis was oriented parallel to the rotational axis and perpendicular to the incoming neutron beam. Fig. 3(a) shows the entire data set from the $\varphi$ scan plotted in the $(h k 0)$ plane. A total of six single-crystal peaks are seen, which correspond to the Miller indices (110), (110), (120), (1 $\overline{2} 0),(2 \overline{1} 0)$ and $(\overline{2} 10)$. This leaves six well defined angular regions where no single-crystal diffraction peaks are present, in other words it is possible to collect data with a very

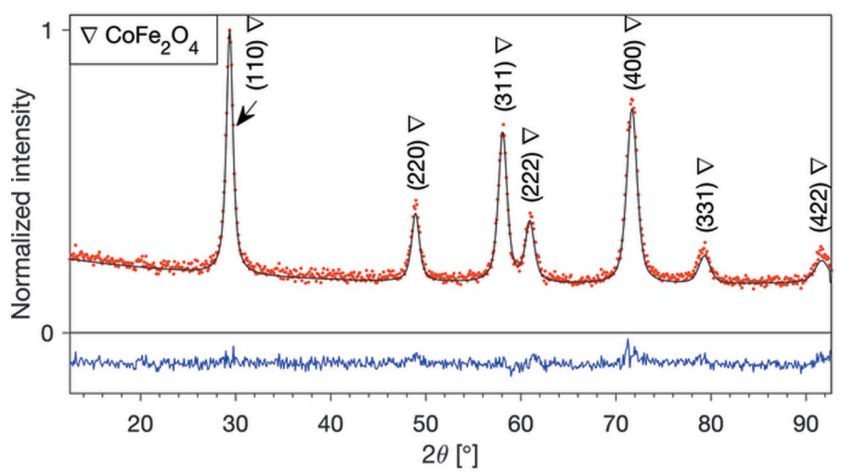

(a)

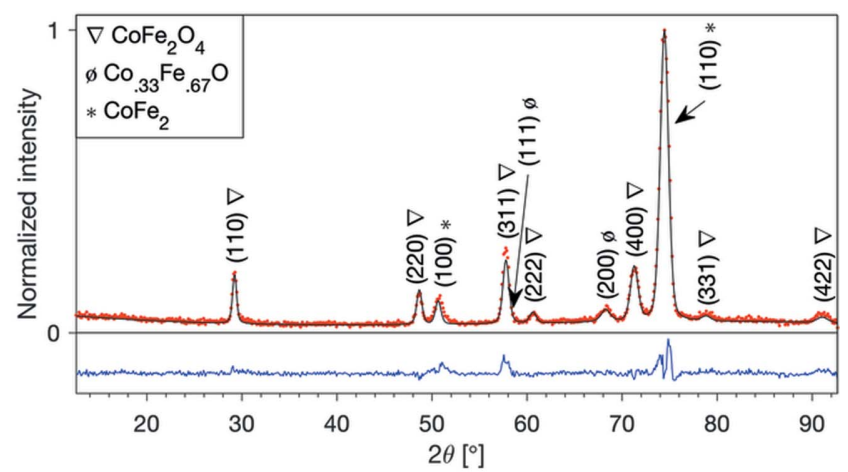

$(b)$

Figure 4

Normalized neutron diffraction data taken at DMC, $\lambda=2.46 \AA$. The sample was measured for 8 min for each data set, with a total neutron count of 50 400. (a) Pristine $\mathrm{CoFe}_{2} \mathrm{O}_{4}$. The model contains a crystallographic and a magnetic phase. (b) Post-reduction data at room temperature. The model now contains $\mathrm{CoFe}_{2} \mathrm{O}_{4}$ (crystallographic and a magnetic phase), $\mathrm{Co}_{0.33} \mathrm{Fe}_{0.67} \mathrm{O}$ (crystallographic phase) and $\mathrm{CoFe}_{2}$ (crystallographic and a magnetic phase). The red dots are data, the black line is the model, and the blue line is the difference between the data and the model 
low background. In addition to the strong single-crystal peaks there are two weak peaks at $2 \theta \simeq 63$ and $70^{\circ}$ that are observed at all $\varphi$ values, i.e. this intensity is originating from a powder. By azimuthally integrating the entire $\varphi$ scan, Figs. 3(b) and $3(c)$ are obtained. Here the smooth background is clearly visible and it is noticeable that the powder intensities do not exceed the background intensity at low angle. The low intensity of the powder peaks makes them disappear into the background of a real experiment. It has not been possible to identify the origin of these peaks.

\subsection{In situ neutron diffraction reduction}

In Fig. 4 the initial and final diffractograms of the experiment are presented. These were Rietveld refined using the program FullProf (Rodríguez-Carvajal, 1993). In the initial data set the model only contains the crystallographic and a magnetic phase of the pristine $\mathrm{CoFe}_{2} \mathrm{O}_{4}$ with space group $F d \overline{3} m$. In the final data set the model contains three crystallographic phases: the spinel $\mathrm{CoFe}_{2} \mathrm{O}_{4}$, the body-centred cubic (b.c.c.) metal alloy $\mathrm{CoFe}_{2}$ (space group $P m \overline{3} m$ ) and the monoxide $\mathrm{Co}_{0.33} \mathrm{Fe}_{0.67} \mathrm{O}$ (space group $\mathrm{Fm} \overline{\mathrm{3}} \mathrm{m}$ ). In addition, the magnetic phases are included for the spinel structure and the alloy. The model fits the data well and parasitic reflections from the sample holder are not observed. Furthermore, the background is flat and reasonably low, which gives a high signal-to-background level even for short exposure times. The background drastically decreases from the initial to the final pattern, which is presumably due to evaporation of water still bound on the surface of the particles after the drying process of the powder at only $323 \mathrm{~K}$.

The peak profile was described using the pseudo-VoigtThomas-Cox-Hastings profile function, where only the Lorentzian contribution was refined. The apparent crystallite sizes were calculated by using the Scherrer equation (Patterson, 1939). The $\mathrm{CoFe}_{2} \mathrm{O}_{4}$ phase grows from 13.2 (3) to 53 (2) nm, while the $\mathrm{Co}_{0.33} \mathrm{Fe}_{0.67} \mathrm{O}$ and $\mathrm{CoFe}_{2}$ phases have a final apparent crystallite size of 23 (1) and 50 (1) nm, respectively. An average magnetic moment of the $\mathrm{Co}$ and $\mathrm{Fe}$ in the $\mathrm{CoFe}_{2} \mathrm{O}_{4}$ phase was refined at room temperature and

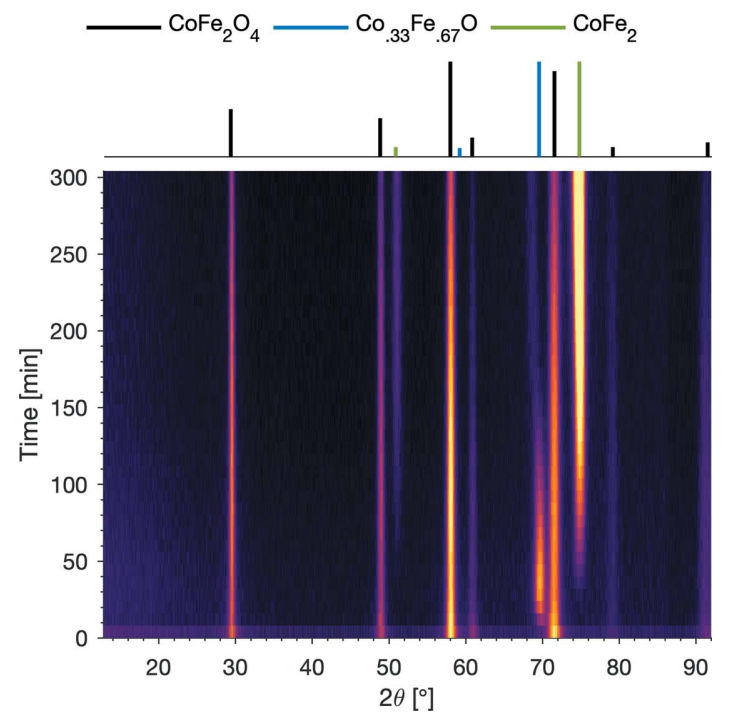

Figure 5

In situ diffraction data of the reduction of $\mathrm{CoFe}_{2} \mathrm{O}_{4}$ as a function of reduction time. Three phases appear in the course of the experiment, which are visualized above the figure. Dark colours are low intensity, bright colours are high intensity.

increases from the initial to the final measurement from 2.02 (5) to 2.19 (6) $\mu_{\mathrm{B}}$ respectively.

The in situ neutron data are presented in Fig. 5 as a function of $2 \theta$ and time $(t)$; the intensity is given by the colour scale. The data quality allows for sequential refinement of all the patterns by using the model from the initial and final data sets (Fig. 4). It is possible not only to follow the phase transitions during the experiment but also to refine occupancies on metallic sites consisting of both $\mathrm{Fe}$ and $\mathrm{Co}$, owing to the contrast in scattering length between the two (GranadosMiralles et al., 2018). Furthermore, it is possible to follow the evolution of the average magnetic moments of $\mathrm{Co}$ and $\mathrm{Fe}$ in $\mathrm{CoFe}_{2} \mathrm{O}_{4}$.

The refined weight fraction as a function of time is presented in Fig. 6(a). At $t=0 \mathrm{~min}$, the spinel $\mathrm{CoFe}_{2} \mathrm{O}_{4}$ is the only observed phase; after $t=8 \mathrm{~min} \mathrm{CoFe}_{2} \mathrm{O}_{4}$ starts reducing to the monoxide $\mathrm{Co}_{0.33} \mathrm{Fe}_{0.67} \mathrm{O}$. The two phases coexist until a sufficient amount of $\mathrm{Co}_{0.33} \mathrm{Fe}_{0.67} \mathrm{O}(\sim 30 \mathrm{wt} \%)$ has been

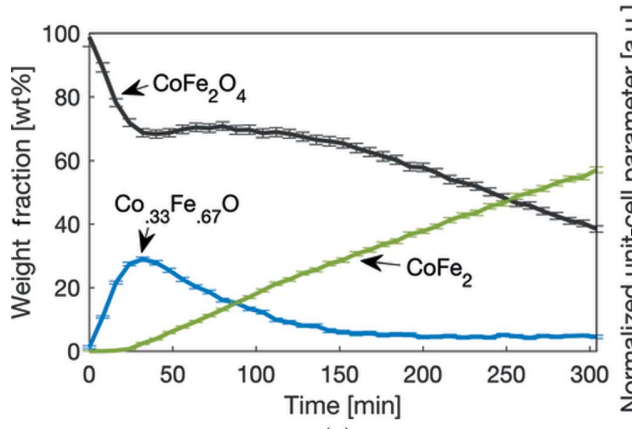

Figure 6

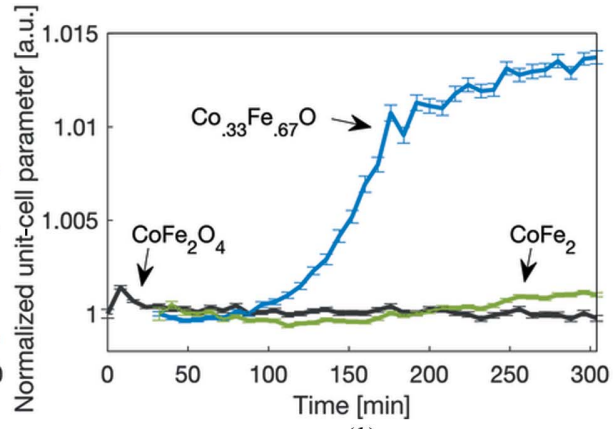

(b)

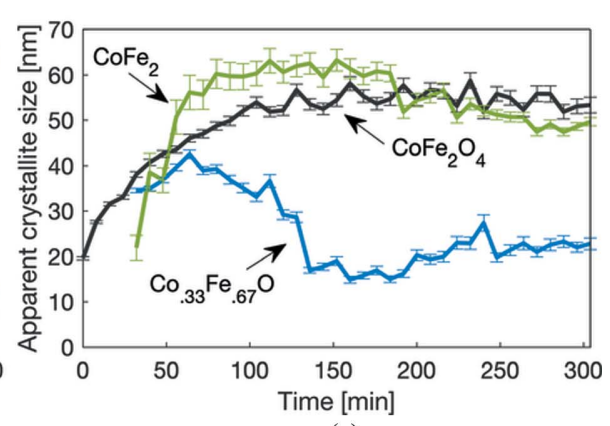

(c)

Refined parameters from sequential Rietveld refinement as a function of time. (a) Weight fraction of $\mathrm{CoFe}_{2} \mathrm{O}_{4}, \mathrm{Co}_{0.33} \mathrm{Fe}_{0.67} \mathrm{O}$ and $\mathrm{CoFe}_{2}$. (b) Unit-cell parameters of $\mathrm{CoFe}_{2} \mathrm{O}_{4}, \mathrm{Co}_{0.33} \mathrm{Fe}_{0.67} \mathrm{O}$ and $\mathrm{CoFe}_{2}$, normalized with respect to the initial values: $8.45223,4.32790$ and $2.87483 \AA$, respectively. (c) Apparent crystallite size of $\mathrm{CoFe}_{2} \mathrm{O}_{4}, \mathrm{Co}_{0.33} \mathrm{Fe}_{0.67} \mathrm{O}$ and $\mathrm{CoFe}_{2}$. 
formed, at which point the metallic b.c.c. alloy $\mathrm{CoFe}_{2}$ starts appearing. This happens after $t=36 \mathrm{~min}$. Once the $\mathrm{CoFe}_{2}$ has been formed almost all of the $\mathrm{Co}_{0.33} \mathrm{Fe}_{0.67} \mathrm{O}$ fully reduces. After $t=144 \mathrm{~min}$, only a small amount of monoxide is still present. At this point the peak position of $\mathrm{Co}_{0.33} \mathrm{Fe}_{0.67} \mathrm{O}$ shifts to a lower angle. The weight fraction of $\mathrm{Co}_{0.33} \mathrm{Fe}_{0.67} \mathrm{O}$ left in the sample after the peak shift stays constant until the end of the experiment, while the reduction of $\mathrm{CoFe}_{2} \mathrm{O}_{4}$ to $\mathrm{CoFe}_{2}$ continues. The experiment was stopped before a full conversion was achieved.

Fig. 6(b) shows the refined normalized unit-cell parameters for all three phases. The unit-cell parameter of $\mathrm{CoFe}_{2} \mathrm{O}_{4}$ increases at $t=8 \mathrm{~min}$, owing to thermal expansion, but subsequently it decreases slowly throughout the experiment. The unit-cell parameter of $\mathrm{Co}_{0.33} \mathrm{Fe}_{0.67} \mathrm{O}$ increases throughout the experiment, with a rapid increase from $t=96 \mathrm{~min}$ to $t=$ $172 \mathrm{~min}$. The unit-cell expansion of $\mathrm{Co}_{0.33} \mathrm{Fe}_{0.67} \mathrm{O}$ suggests that the structure expels $\mathrm{Co}^{2+}$, shifting the unit-cell parameter towards the larger unit cell of $\mathrm{FeO}(4.31 \AA)$ as opposed to that of CoO (4.26 $\AA$ ) (Mattheiss, 1972). The unit-cell parameter of $\mathrm{CoFe}_{2}$ decreases from its first occurrence at $t=32 \mathrm{~min}$ until $t=$ $112 \mathrm{~min}$, after which it increases.

The apparent crystallite sizes are plotted in Fig. 6(c). The apparent crystallite size of $\mathrm{CoFe}_{2} \mathrm{O}_{4}$ increases and plateaus at $\sim 55 \mathrm{~nm}$. The apparent crystallite size of $\mathrm{Co}_{0.33} \mathrm{Fe}_{0.67} \mathrm{O}$ follows the trend of the weight fraction, and it can be concluded that the $\mathrm{Co}_{0.33} \mathrm{Fe}_{0.67} \mathrm{O}$ is consumed by reducing the size of the crystallites. The apparent crystallite size of $\mathrm{CoFe}_{2}$ initially increases together with its weight fraction and then decreases after $t=144 \mathrm{~min}$. It is hypothesized that this is due to phase segregation between $\mathrm{CoFe}$ and $\alpha$-Fe, both having b.c.c. structures, but with $\alpha$-Fe having a slightly larger unit cell, causing an apparent broadening of the diffraction peak. Additional refined parameters can be found in the supporting information [see McCusker et al. (1999) and Toby (2006) for additional literature related to the analysis of this material].

The appearance of the monoxide in the product after reduction has previously been reported ex situ (Zhang et al., 2013; Quesada et al., 2016). Only recently have GranadosMiralles et al. (2018) been able to follow the reduction process in situ, using synchrotron radiation. In the reported study the monoxide was discovered as an intermediate phase in a twostep reduction following $\mathrm{CoFe}_{2} \mathrm{O}_{4} \rightarrow \mathrm{Co}_{0.33} \mathrm{Fe}_{0.67} \mathrm{O} \rightarrow \mathrm{CoFe}_{2}$ rather than a phase appearing as a re-oxidization process. The data presented in Figs. 5 and 6 show the same trends as observed by Granados-Miralles and co-workers.

\section{Conclusion}

The single-crystal sapphire air-gun heater setup (SAHS) was presented. It is designed for solid-gas in situ monochromatic angular dispersive powder neutron diffraction and it can be mounted onto the sample table of almost any neutron diffractometer capable of monochromatic angular dispersive measurements.

A $\varphi$ scan of the single-crystal sapphire sample holder showed that, by rotating the tube, it is possible to obtain an orientation with a very low and flat background with no parasitic reflections. A temperature calibration showed a sample temperature range from 300 to $973 \mathrm{~K}$ with a fast heating rate and a sample temperature stabilization time of less than 5 min.

The SAHS has been successfully used at the DMC instrument at SINQ to follow a reduction experiment of $\mathrm{CoFe}_{2} \mathrm{O}_{4}$ in situ in an effort to control the production of exchange-spring permanent magnets. From sequential refinement of the in situ neutron diffraction data, it was confirmed that the reduction happens through an intermediate phase in a two-step reduction in the sequence $\mathrm{CoFe}_{2} \mathrm{O}_{4} \rightarrow \mathrm{Co}_{0.33} \mathrm{Fe}_{0.67} \mathrm{O} \rightarrow \mathrm{CoFe}_{2}$. The data quality furthermore allows for refinement of apparent crystallite size as well as magnetic moments.

With a time resolution of 8 min per pattern and a sample volume of $\sim 2 \mathrm{~cm}^{3}$, it is possible to follow solid-gas reactions on a realistic timescale and with a larger sample size compared with similar experiments performed using X-rays, moving the application towards conditions seen in industry. The setup can be used to understand how advanced materials act under nonambient conditions.

\section{Acknowledgements}

This work is based on experiments performed at the Swiss spallation neutron source SINQ, Paul Scherrer Institute, Villigen, Switzerland. Affiliation with the Center for Integrated Materials Research (iMAT) at Aarhus University is gratefully acknowledged.

\section{Funding information}

The authors would like to thank the Danish National Research Foundation (Center for Materials Crystallography, DNRF-93), Innovation Fund Denmark (Green Chemistry for Advanced Materials, GCAM-4107-00008B), and the Danish Center for Synchrotron and Neutron Science (DanScatt) for financial support.

\section{References}

Akhtar, S. S., Arif, A. F. M. \& Yilbas, B. S. (2012). Int. J. Adv. Manuf. Technol. 58, 57-70.

Als-Nielsen, J. \& McMorrow, D. (2011). Elements of Modern X-ray Physics. Chichester: Wiley.

Andersen, H. L. \& Christensen, M. (2015). Nanoscale, 7, 3481-3490.

Andersen, H. L., Granados-Miralles, C., Saura-Múzquiz, M., Stingaciu, M., Larsen, J., Søndergaard-Pedersen, F., Ahlburg, J. V., Keller, L., Frandsen, C. \& Christensen, M. (2019). Mater. Chem. Front. 3, 668-679.

Bhattacharyya, S. (2015). J. Phys. Chem. C, 119, 1601-1622.

Busing, W. R. \& Levy, H. A. (1967). Acta Cryst. 22, 457-464.

Chen, Q. L., Holdsworth, S., Embs, J., Pomjakushin, V., Frick, B. \& Braun, A. (2012). High Pressure Res. 32, 471-481.

Eikeland, A. Z., Stingaciu, M., Granados-Miralles, C., SauraMuzquiz, M., Andersen, H. L. \& Christensen, M. (2017). CrystEngComm, 19, 1400-1407.

Giacovazzi, C., Monaco, H. L., Artioli, G., Viterbo, D., Milanesio, M., Gilli, G., Gilli, P., Zanotti, G., Ferraris, G. \& Catti, M. (2011). Fundamentals of Crystallography, 3rd ed. Oxford University Press. 
Götze, A., Auer, H., Finger, R., Hansen, T. \& Kohlmann, H. (2018). Physica B, 551, 395-400.

Granados-Miralles, C., Saura-Múzquiz, M., Andersen, H. L., Quesada, A., Ahlburg, J. V., Dippel, A.-C., Canévet, E. \& Christensen, M. (2018). ACS Appl. Nano Mater. 1, 3693-3704.

Hansen, B. R. S., Møller, K. T., Paskevicius, M., Dippel, A.-C., Walter, P., Webb, C. J., Pistidda, C., Bergemann, N., Dornheim, M., Klassen, T., Jørgensen, J.-E. \& Jensen, T. R. (2015). J. Appl. Cryst. 48, 12341241.

Klotz, S. (2012). Techniques in High-Pressure Neutron Scattering. Boca Raton: CRC Press.

Kohlbrecher, J., Bollhalder, A., Vavrin, R. \& Meier, G. (2007). Rev. Sci. Instrum. 78, 125101.

Kohlmann, H., Kurtzemann, N., Weihrich, R. \& Hansen, T. (2009). Z. Anorg. Allg. Chem. 635, 2399-2405.

Loopstra, B. O. \& Rietveld, H. M. (1969). Acta Cryst. B25, 787-791. Mattheiss, L. F. (1972). Phys. Rev. B, 5, 290-306.

McCusker, L. B., Von Dreele, R. B., Cox, D. E., Louër, D. \& Scardi, P. (1999). J Appl Cryst. 32, 36-50.

Meka, S. R., Chauhan, A., Steiner, T., Bischoff, E., Ghosh, P. K. \& Mittemeijer, E. J. (2016). Mater. Sci. Technol. 32, 883-889.

Okuchi, T., Hoshikawa, A. \& Ishigaki, T. (2015). Metals, 5, 2340-2350.

Patterson, A. L. (1939). Phys. Rev. 56, 978-982.

Peters, J., Trapp, M., Hughes, D., Rowe, S., Demé, B., Laborier, J. L., Payre, C., Gonzales, J. P., Baudoin, S., Belkhier, N. \& LelièvreBerna, E. (2012). High Pressure Res. 32, 97-102.
Quesada, A., Granados-Miralles, C., López-Ortega, A., Erokhin, S., Lottini, E., Pedrosa, J., Bollero, A., Aragón, A. M., Rubio-Marcos, F., Stingaciu, M., Bertoni, G., de Julián Fernández, C., Sangregorio, C., Fernández, J. F., Berkov, D. \& Christensen, M. (2016). Adv. Electron. Mater. 2, 1500365.

Rauch, H. \& Waschkowski, W. (2003). Neutron Data Booklet, 2nd ed., edited by A.-J Dianoux \& G. Lander, ch. 1.1. Philadelphia: OCP Science.

Rietveld, H. M. (1969). J. Appl. Cryst. 2, 65-71.

Rodríguez-Carvajal, J. (1993). Physica B, 192, 55-69.

Rondinone, A. J., Jones, C. Y., Marshall, S. L., Chakoumakos, B. C., Rawn, C. J. \& Lara-Curzio, E. (2003). Can. J. Phys. 81, 381-385.

Sakintuna, B., Lamaridarkrim, F. \& Hirscher, M. (2007). Int. J. Hydrogen Energy, 32, 1121-1140.

Sidhu, S. S., Heaton, L. R., Zauberis, D. D. \& Campos, F. P. (1956). J. Appl. Phys. 27, 1040-1042.

Stingaciu, M., Andersen, H. L., Granados-Miralles, C., Mamakhel, A. \& Christensen, M. (2017). CrystEngComm, 19, 3986-3996.

Toby, B. H. (2006). Powder Diffraction, 21, 67-70.

Widenmeyer, M., Niewa, R., Hansen, T. C. \& Kohlmann, H. (2013). Z. Anorg. Allg. Chem. 639, 285-295.

Zaliznyak, I. A. \& Lee, S. H. (2004). Magnetic Neutron Scattering. Brookhaven National Laboratory, United States.

Zhang, Y., Xiong, R., Yang, Z., Yu, W., Zhu, B. P., Chen, S. \& Yang, X. F. (2013). J. Am. Ceram. Soc. 96, 3798-3804.

Züttel, A. (2004). Naturwissenschaften, 91, 157-172. 